\title{
COMUNISMO E GÊNERO NO ESCOLA SEM PARTIDO: NOTAS PARA NÃO SUCUMBIR A UMA PEDAGOGIA FASCISTA
}

\author{
Cássia Cristina Furlan (UFGD)* \\ https://orcid.org/0000-0002-8175-9320 \\ Fabiana Aparecida de Carvalho (DBI/UEM)** \\ https://orcid.org/0000-0002-6746-4200
}

\section{RESUMO}

Objetiva-se traçar uma genealogia do Movimento Escola sem Partido quanto à elaboração de discursividades que vinculam os estudos de gênero aos ideários comunistas. Via pesquisa e análise documental dos estatutos de Projetos de Lei, de notas técnicas, de Requerimentos de Informação e de algumas publicações em sites do Movimento, evidenciam-se os aparatos discursivos a impor uma visão de neutralidade nas escolas, combativa da doutrinação e dos processos de subversão moral provadas pelos debates de gênero. Critica-se a visão restritiva do Escola sem Partido e sua promoção de uma pedagogia fascista.

Palavras-chave: Estudos de gênero. Discursividades. Escola sem Partido.

\section{ABSTRACT \\ COMMUNISM AND GENDER IN UNPOLITICAL SCHOOL: NOTES NOT TO SUCCEED TO A FASCIST PEDAGOGY}

The objective is to trace a genealogy of the Unpolitical School Movement regarding the elaboration of discursivities that link Gender Studies to Communist ideas. Through research and documentary analysis of the statutes of Law Projects, Technical Notes, Information Requirements and some publications on the Movement's websites, the discursive apparatus to impose a view of neutrality in schools, combating indoctrination and processes, is evident. of moral subversion proved by the Gender debates. The restrictive view of Unpolitical School is criticized and its promotion of a fascist pedagogy.

Keywords: Gender studies. Discourse. Unpolitical school.

Doutora em Educação pela Universidade Estadual de Maringá (UEM). Professora Adjunta e Coordenadora do Curso de Educação Física na Universidade Federal de Grande Dourados (UFGD). Líder do Grupo de estudos e pesquisas em Educação Física e Cultura(s) (EDUCA). E-mail: cassiacfurlan@gmail.com

** Doutora em Educação para a Ciência e a Matemática pela Universidade Estadual de Maringá (UEM). Professora Adjunta do Departamento de Biologia da Universidade Estadual de Maringá (DBI/UEM). Coordenadora do Grupo de Estudos das Pedagogias do Corpo e da Sexualidade (GEPECOS). E-mail: facarvalho@uem.br 


\section{RESUMEN \\ COMUNISMO Y GÉNERO EN LA ESCUELA SIN PARTIDO: NOTAS PARA NO TENER ÉXITO EN UNA PEDAGOGÍA FASCISTA}

El objetivo es rastrear una genealogía del movimiento Escuela Sin Partido con respecto a la elaboración de discursividades que vinculan los estudios de género con las ideas comunistas. A través de la investigación y el análisis documental de los estatutos de proyectos de ley, notas técnicas, requisitos de información y algunas publicaciones en los sitios web del Movimiento, es evidente el aparato discursivo para imponer una visión de neutralidad en las escuelas, combatir el adoctrinamiento y los procesos. de subversión moral demostrada por los debates de género. Se critica la visión restrictiva de Escuela sin Partido y se promueve una pedagogía fascista.

Palabras clave: Estudios de género. Discurso. Escuela sin Partido.

\section{...Dos discursos e verdades}

\section{(inventadas) que se repetem...}

No dia 11 de novembro de 1970, o Coronel Rubens Resstel proferiu, no Clube Círculo Militar de São Paulo, a explanação "Infiltração Comunista nos meios Educacionais" (RESSTEL, 1970), destinada a professoras(es) e gestoras(es) educacionais da rede estadual e particular e a convidadas(os) do então Secretário de Educação do Estado Paulo Ernesto Tolle. O militar, munido do ideário de prestação de serviços à causa da educação, da segurança nacional e de preservação do regime ditatorial em vigência, tentava alertar as autoridades escolares e docentes presentes sobre os perigos decorrentes dos métodos e táticas utilizadas por agentes da subversão no meio estudantil. Ancorado no que denominou de gravidade e extensão de aspectos e fatos a confrontar a verdadeira natureza didático-pedagógica e administrativa, acenara para os casos de instalação ideológica nas escolas secundaristas e nos meios universitários, incentivando a abertura de inquéritos e denúncias de escolas, a aplicação de regulamentos disciplinares e o reestabelecimento da normalidade pautada na ordem imperativa do já decretado Ato Institucional $n^{\circ} 5$, de 1968 .

1 De acordo com a Plataforma Brasil, o artigo está dispensado de registro de termos de consentimento por se tratar de pesquisa documental, sem utilização de seres humanos.
O Serviço de Segurança Nacional da época acreditava piamente que as/os comunistas coligados aos partidos políticos e às frentes de influência procuravam se infiltrar nas faculdades de Ciências Sociais, de Comunicações e de Filosofia, Ciências e Letras - tidas como locais de formação docente e de influência intelectual em outros meios estudantis - para disseminar junto às/aos alunas(os) toda espécie de informação tóxica e subversiva, entre elas o amor livre, a atração sexual desenfreada, a perseguição ao pudor feminino e a adoção do pensamento crítico.

$\mathrm{Na}$ esteira desse pensamento ideológico, Resstel (1970) mantinha a convicção de que a liberdade de cátedra seria um método largamente utilizado pelos agentes doutrinadores no magistério, uma vez que esses se valiam de suas posições de prestígio para conquistar a mente de jovens imaturos e predispô-los, ao manipular suas emoções, ao aliciamento, à contestação, ao protesto e à dúvida acerca da seguridade do regime militar. 0 coronel criticou a "exagerada autonomia didática e administrativa" de professoras(es) e diretoras(es) como desencadeadora de proselitismos e, consequentemente, de falhas de organização escolar, de desinformação e de despreparo das autoridades de ensino para reconhecer as suti- 
lezas psicológicas e discursivas disseminadas pelas(os) militantes nos espaços educacionais. A título de exemplificação, seu discurso congregou ataques aos conteúdos, técnicas de ensino e métodos importados tidos como perniciosos e sujeitos a propósitos ocultos; o "estudo do meio", método interdisciplinar que favorece a imersão e o contato direto com uma dada realidade a ser estudada, na acepção de Resstel (1970), fora visto como técnica didático-pedagógica a depor sobre os aspectos positivos da vida social, sendo o responsável por enfraquecer o poder da autoridade, por atrair a adolescência para o vício, para a marginalização social e para uma atuação política de esquerda.

Ao término de sua apresentação, o coronel exortou o papel de dirigentes de ensino, orientadoras(es) educacionais e docentes para com as responsabilidades do cumprimento da segurança nacional e, enfaticamente, lembrou as pessoas presentes que máquinas subversivas promovem "inocentes ou idiotas úteis" 2 (RESSTEL, 1970) nos estabelecimentos de ensino, e que o Brasil, via militares, havia definido sua opção ideológica em março de 1964, deixando registrado, nas entrelinhas do discurso, um rol de intenções para a implantação de uma pedagogia de cunho fascista nas escolas.

Cinquenta anos separam esse episódio do Governo Jair Bolsonaro, no entanto, as ideias pronunciadas lá, nesse passado não tão remoto, parecem estar mais vívidas e propagadas aqui, na atualidade política do país e na reintegração de militares do alto e baixo escalão à frente de ministérios e gabinetes do novo governo.

Em meio ao cenário de movimentações e

2 No jargão político atual, o termo "idiota útil", originalmente cunhado por vertentes comunistas e socialistas para se referir às pessoas alienadas da realidade imposta pelo capitalismo, tem sido utilizado por setores sociais de ultradireita para nomear as/os simpatizantes de posições esquerdo-partidárias ou mesmo aquelas(es) contrárias(os) ao neoliberalismo, às desigualdades geradas pelo regime econômico e pelo lucro e às medidas adotadas pelo governamento atual do país. Mantemos a acepção atual por ela se alinhar à explicação dada na fala de Resstel e no alinhamento do Movimento Escola sem Partido, objeto de crítica desta comunicação. de guinadas ao conservadorismo e ao recrudescimento do Estado quanto ao subsídio de políticas públicas, assistenciais e de direitos humanos, o Brasil se vê a repetir a evocação de dois fantasmas acionados de modo complementar ou como sinônimos. Essa evocação parece ressurgir nos períodos de crises e desmandos administrativos que desestabilizam a gestão pública e o desenvolvimento econômico. Assim sendo, na história recente do país, demarcada após o golpe de 1964, comunismo e gênero funcionaram e funcionam como disparadores de pânicos morais e políticos na população e como ameaças a uma pretensa ordem social e a um projeto de nação ancorado nos valores tradicionais das elites dominantes.

0 destaque inicial feito ao pronunciamento de Resstel (1970) não é uma recorrência simples a um fato histórico. Em nosso entendimento, trata-se, conforme apontado por Michel Foucault (1984), de realizar uma operação genealógica e de trazer a discursividade do que já vivemos com o intento de presentificar a atualidade histórica e política e de compreender como certos enunciados, discursos e práticas inventam-se, circulam e se estabelecem como falas, ações e posturas de alguns grupos sociais no cerne de um processo de reiteração de argumentos de autoridade ou do estabelecimento de uma verdade única e absoluta sobre os fatos.

Se apagássemos os nomes, locais e datas registrados no Círculo Militar e sugeríssemos a associação dos encadeamentos apontados acima ao momento histórico-político brasileiro, certamente, muitas das(os) leitoras(as) poderiam traçar caminhos a conectar a explanação inicial desta comunicação a figuras contemporâneas cujos perfis se engajam numa espécie de perseguição anticomunista. Seriam, provavelmente, citados nomes como os de: Miguel Nagib, advogado católico, e sua confabulação acerca da doutrinação como um abuso de professoras(es) da liberdade de ensinar e do princípio da imparcialidade; Rodrigo Constantino, 
jornalista, propagador de matérias jornalísticas deturpadas sobre a militância comunista e a ocupação de universidades e escolas por diretórios partidários; Bia Kicis, deputada do PSL-DF, que refuta as evidências científicas e estudos objetivos ao propagar supostos fatos, denúncias e postagens em rede sociais na internet com o mote de sonegação de conteúdos às / aos alunas(os) em prol do comunismo, do feminismo e das deturpações do gênero; e a família Bolsonaro com seus discursos congregados de incentivos às violências, aos denuncismos e ao extermínio de militantes de esquerda. Além de suas convicções sobre sociedade e política, essas pessoas têm em comum a associação ao Movimento Escola sem Partido.

Desde 2014, após a votação dos Planos de Educação nas unidades federativas do país e pelo Congresso Nacional, e dos embates religiosos pela supressão das metas concernentes a igualdade e equidade de gênero nos documentos elaborados (TOLOMEOTTI; CARVALHO, 2016), o Escola sem Partido (ESP) vem sendo encampado por baluartes e políticas(os) apropriadores da causa para a reafirmação de alinhamentos mercadológicos, da redução do papel do Estado e para a operacionalização de uma visão moralizante da escola pública, da educação básica e do pensamento crítico.

Nossa intenção é traçar uma genealogia e colocar em evidência as justificativas e os mecanismos com os quais o Movimento Escola sem Partido tem dado ênfase e vincula o gênero como sinônimo de comunismo e, por associação, como ferramenta de perversão dos ideários políticos, de supostas regras naturais que determinam os corpos e a sociedade e dos ensinamentos escolares.

A compreensão a guiar a linha analítica desta comunicação está ancorada nas epistemologias feministas que abarcam o gênero como uma categoria semântica e política, uma lente para se compreender a construção de diferenças, de igualdade, de equidade, de dominações ou de libertações na vida social a partir de papéis atribuídos ou desem- penhados por pessoas e da construção de masculinidades e de feminilidades (FURLAN; CARVALHO, 2019). Tomamos a categoria gênero também com um dispositivo histórico que engendra representações, normas e condutas sociais e como uma possibilidade de abarcar significados nem sempre tão evidentes quando se intersectam posições de classe, de raça e de subjetividade.

Para atingir nossa proposição, lançamos mão da leitura/análise documental de produções como: 1) Projetos de Lei (PL), entre os quais: PL n ${ }^{\circ} 7.180 / 2014^{3}$ (BRASIL, 2014a), proposto por Erivelton Santana (PSC-BA); PL n ${ }^{\circ}$ 867/2015 (BRASIL, 2015a), de autoria do Deputado Izalci Lucas (PSDB-DF); PL $\mathrm{n}^{\circ}$ 193/2016 (BRASIL, 2016), do Senador Magno Malta (PL-ES), já retirado de pauta; PL ${ }^{\circ}$ 246/2019 (BRASIL, 2019), apresentado pela deputada Bia Kicis (PSL-DF); 2) Notas Técnicas do Escola sem Partido (NAGIB et al., 2018); 3) Publicações do site escolasempartido.org (ESCOLA SEM PARTIDO, 2020); e 4) o Requerimento de Informação (RIC) n ${ }^{\circ} 565 / 2015$ (BRASIL, 2015b), redigido por Izalci Lucas (PSDB-DF), Cesar Souza (PSD-SC), Diego Garcia (PHS-PR) e Eduardo Cury (PSDB-SP).

Nessa linha genealógica ${ }^{4}$ tentamos compreender a emergência de configurações, redes de interesse, dispositivos e significações atreladas aos discursos e práticas fundantes (FOUCAULT, 1984) do Movimento Escola sem

3 Optamos por explorar alguns Projetos de Lei vinculados à defesa de uma educação baseada na pseudoneutralidade política e contra a pretensa "Ideologia de Gênero". No entanto, existem vários projetos tramitando (e/ ou arquivados/retirados de pauta), em conjunto e/ou individualmente, na Câmara dos Deputados e em outras instâncias legislativas, visando a objetivos semelhantes. Citamos alguns: PL no 5.487/2016, apensado ao PL no 1.859/2015; PLs ${ }^{\text {os }} 7.181 / 2014$ e $867 / 2015$, apensado ao PL 7.180/2014; e o PL no 1.411/2015, dentre outros.

4 Nossa pretensão não é dispor uma análise do discurso habitual sobre o Escola sem Partido. As reflexões aqui levantadas guiam-se pela noção de genealogia aportada em Foucault (1984), destacando os vínculos aos quais o Movimento associa-se, como ele emerge nos acontecimentos recentes do País e sua correlação de forças nesse momento em termos de suas estratégias, táticas e discursividades para se impor como um processo de dominação e como um projeto educacional para o Brasil. 
Partido e de como ele configura a aversão ao comunismo e ao gênero como estratégia de convencimento tanto no campo estratégico do poder político, quanto no domínio de uma vontade de saber imposta para escolas. Com isso, buscamos provocar reflexões sobre os modos como tais aparatos de produção discursiva, aliados a uma pretensa neutralidade e balizados pela suposição de combate a um ensino com fins políticos, ideológicos e partidários, produzem um imaginário social de suposta doutrinação e subordinação aos princípios comunistas e de subversão da moral alicerçada aos debates de gênero, discutindo tais implicações para a educação e para a democracia.

Trazemos uma contextualização da invenção do Movimento no Brasil seguida de nossa compreensão sobre a atribuição de sentidos ao comunismo e ao gênero visando apontar caminhos e possibilidades para análise dos processos de subordinação às lógicas discursivas produzidas pelo ESP e suas/seus idealizadoras(es). Assim, pretende-se desconstruir os caminhos discursivos que impõem medo e coação ao trabalho docente, caminhando para a produção de resistências aos movimentos persecutórios que têm se instalado no cenário nacional, objetivando não sucumbir à uma pedagogia fascista.

\section{Escola sem partido: breve visão} de uma pedagogia de controle

Para efeito didático de contextualização, o Movimento Escola sem Partido é inventado em 2004, pelo advogado paulista Miguel Nagib, que se apropria de ideias reacionárias de movimentos conservadores norte-americanos e de projetos neoliberais encampados por corporações transnacionais conhecidas como think tanks, ${ }^{5}$ especialmente com o objetivo de

5 Instituto Millenium e Instituto Liberal são exemplos de think tanks vinculados a Miguel Nagib e ao Escola sem Partido. Essas organizações são conhecidas, entre outros propósitos educacionais, pela ênfase na transformação da educação em mercadoria, pela defesa da privatização do contestar currículos escolares e a liberdade de cátedra de professoras(es) (CARVALHO; POLIZEL; MAIO, 2016). Nagib forja um movimento de defesa das escolas baseado, inicialmente, na interpretação dos princípios de imparcialidade de posições nas instituições de ensino e da corresponsabilidade Estado-Família-Escola na educação de crianças e jovens.

0 que seria, aparentemente, uma evocação da liberdade de expressão nos espaços de ensino e a luta para que fatos históricos fossem apresentados sob mais de um ponto de vista, transformou-se, pela influência de Olavo de Carvalho e de seu pensamento de combate a uma guerra cultural orquestrada por teóricas(os) marxistas e socialistas reticentes ao cristianismo e aos valores morais tradicionais (PENNA; SALLES, 2017), numa cruzada a perseguir explicações, conceitos e posições divergentes da versão hegemônica sobre a história, sobre a ciência e sobre aquilo que é tido como norma social.

A grande explosão do Movimento, em termos de adesão e simpatia à sua filosofia, dá-se em 2014, quando o então Deputado Flávio Bolsonaro protocola o primeiro Projeto de Lei Escola sem Partido na Assembleia Legislativa do Estado do Rio de Janeiro. Encomendado primeiramente pelos Bolsonaros, o Projeto transforma-se em uma minuta disponibilizada na internet para que políticas(os) dos Estados e Municípios e pessoas interessadas possam copiar e garantir a representatividade do movimento em casas legislativas, em seus núcleos escolares e familiares.

As/os coligadas(os) ao Escola sem Partido difundem em canais midiáticos de rádio, televisão e da internet suas palestras, cartilhas e explicações propagadoras de críticas ao que chamam de marxismo cultural e de desconstrução aos valores cristãos. Segundo Miguel (2016), a posição reacionária manifesta coop-

sistema público de ensino, pela defesa da implantação do homescholling, "sala de aula invertida" e ensino a distância como estratégias minimizadoras de investimentos e gastos com educação e pelo incentivo à interferência de grupos privados nas escolas. 
ta ideários de libertarianismo econômico (redução das subvenções econômicas do Estado, incentivo ao empreendedorismo individual e do livre mercado e regulamentação da vida privada), de fundamentalismo religioso e de anticomunismo - este direcionado, agora, à perseguição ao Partido do Trabalhadores (PT) e demais frentes de centro-esquerda no país. Segundo Nagib e outros (2018), há uma coleção de evidências de práticas abusivas nas escolas, que se presta à alimentação de acervos online contendo artigos, reportagens, depoimentos gravados em áudios e vídeos, denúncias de livros didáticos, de eventos, de escolas e de educadoras(es) (ESCOLA SEM PARTIDO, 2020).

Em nosso ponto de vista, a base ideológica do Escola sem Partido encontra-se assentada em "discursividades" responsáveis por criar concepções enviesadas da escola e do processo educativo. Por "discursividades" entendemos uma série de discursos, narrativas, práticas e enunciados a marcar representações, estereótipos, posições ideológicas que se correlacionam com a criação de significados, com as relações de poder e com a imposição de verdades. Elas emergem de contextos de época, grupos, economia, de certas visões de ciência e são transitórias, logo, seus estatutos são relacionais e dependentes de conjunturas acontecimentais que favorecem suas dispersões e validades.

A conjuntura histórica do Brasil após as movimentações de rua do ano de 2013, exigindo melhores condições sociais e o fim da corrupção, o processo de afastamento da Presidenta Dilma Rousseff e a forja do Golpe Parlamentar em 2016, o fortalecimento dos setores conservadores e de bancadas políticas religiosas nas casas legislativas com a representatividade do agronegócio, das facções e milícias pró-armamento da população e dos setores religiosos (conformando as bancadas do "Boi" da "Bala" e da "Bíblia") são exemplos de acontecimentos que operaram as condições acontecimentais para que os discursos antiesquerda se forta- lecessem como a verdade de certos grupos e para que a reatividade do Escola sem Partido pudesse povoar o imaginário de muitas pessoas. Logo, nos últimos dois anos, o Movimento cresceu em representatividade, sendo defendido por partidos como o PSC, PSL, PP e PSDB, grupos empresariais ligados a sistemas de ensino privados, legisladores que defendem interesses de igrejas e por organizações como o Movimento Brasil Livre.

O ESP está amplamente empenhado em ditar regras para as escolas com o propósito da descontaminação das instituições, das doutrinações e ideologias partidárias e subordinação à neutralidade do conhecimento (NAGIB et al., 2018). Suas proposições, mais que simples códigos de preceitos afixados nas paredes de colégios e universidades, visam agir diretamente: a) na Lei de Diretrizes e Bases da Educação (LDB/1996), ao instaurar práticas de vigílias e punições às/aos educadoras(es); b) no Programa de Distribuição do Livro Didático, extinguindo a política pública que dota a escola de livros avaliados por equipes competentes e por padrões que se adequam aos conteúdos estruturantes da educação básica; e c) na liberdade de cátedra de professoras(es) e escolha dos conteúdos escolares.

Nas premissas de coibir a livre expressão nas escolas brasileiras, vigiar docentes em suas liberdades de ensino e expressão, cercear os conteúdos curriculares que possuem importância na construção da cidadania, o Escola sem Partido, ainda que não seja Lei, mas com o argumento de Lei, vai se estabelecendo como uma perigosa política de delação, censura e punição que afetará a vida de professoras(es), de equipes gestoras e de estudantes, instaurando uma pedagogia arregimentada do medo e da opressão.

Dessa maneira, constela-se o perfil desse movimento social conservador que, junto a outros mais reativos, passa a disseminar, além do pânico aos posicionamentos de esquerda, dispositivos de controle e negação à educação dos gêneros e à diversidade sexual. 


\section{A atribuição de sentidos}

\section{ao comunismo e gênero: a invenção da verdade escola sem partido}

As premissas do Movimento - alicerçadas em enunciados falaciosos e recheados de interesses - constroem a ideia de uma escola doutrinadora e moralmente deturpada, que precisa ser defendida já que sua gestão é maculada por educadoras(es), instituições gestoras e pelo próprio Ministério da Educação (MEC), que congrega, na visão das(os) defensoras(es) escola-apartidárias(os), uma pecha de comunistas instalados nos gabinetes e secretarias após as gestões do Presidente Luís Inácio Lula da Silva (2003-2011) e da Presidenta Dilma Rousseff (2011-2016). De carona com essa concepção, órgãos governamentais e de ensino subordinados ao MEC, entre os quais as Universidades, tornam-se alvos de generalizações e de reducionismos tendenciosos a corromper a capacidade de gestão, de diálogo e de moral.

No tocante ao reconhecimento dos estudos, militâncias, proposições ou mesmo de intervenções pedagógicas envolvendo debates sobre gênero, uma série de episódios vai marcando o cenário das políticas e antipolíticas brasileiras. Como já evidenciado, acompanhamos um processo de disputa pela produção de verdades na consolidação do Plano Nacional de Educação (PNE).

A proposição inicial do PNE, conforme destacada no Inciso II do Art. $2^{\circ}$ do PL original (PL no 8.035-B/2010 - aprovada em 16/10/2012) encaminhado ao Senado pela Câmara dos Deputados, inicialmente estabelecia como uma das diretrizes do documento: "a superação das desigualdades educacionais, com ênfase na promoção da igualdade racial, regional, de Gênero e de orientação sexual e na erradicação de todas as formas de discriminação" (BRASIL, 2010). A redação proposta endossava pontos fundamentais anteriormente debatidos pela Organização das Nações Unidas (ONU) na Con- ferência Mundial sobre a Mulher de Pequim, em 1995, e na Conferência de Direitos Humanos de Yogyakarta, em 2006, às quais o Brasil foi país signatário e assinou uma carta de proposições comprometendo-se com as medidas favorecedoras da equidade para os gêneros e com a erradicação das desigualdades para as mulheres e para as pessoas LGBT+.

Face às pressões de oposição derivadas de fundamentalistas e facções religiosas, do conservadorismo e da amplamente disseminada perseguição ao termo gênero, assistimos a um apagamento deliberado da especificação de formas mais graves de desigualdade. Por votação, opta-se pela retirada do gênero do PNE original, permanecendo, no Plano em vigor desde 2014 (Lei no 13.005/2014, publicada em 25/06/2014), apenas uma diretriz genérica acerca da erradicação de todas as formas de discriminação (BRASIL, 2014b). 0 mesmo aconteceu, posteriormente, e de forma mais acirrada, na aprovação dos Planos Estaduais, Municipais e Distrital de educação, deflagrando a tomada das casas legislativas por posições não laicas e por motivações antigêneros a resultar em dispositivos legais a incitar uma "caça às bruxas" e aos preceitos categorizados supostamente comunistas e de "Ideologia de Gênero".

Percebe-se, a partir de então, uma movimentação de captura de um neologismo, inicialmente fundado nos setores radicais católicos a partir do pontificado de Bento XVI (GABARGNOLI; PREARO, 2017) e mais tarde cooptado por posicionamentos canônicos de grupos religiosos - a "Ideologia de Gênero", por organizações político-partidárias ou suprapartidárias como o Movimento Brasil Livre e o próprio Escola sem Partido.

Nesse contexto, estabelecem-se redes de apoio e agenciamento do Escola sem Partido responsáveis por uma série de PLs que contradizem a filosofia de não vínculo a nenhum

6 0 neologismo nasce na Igreja Católica Romana como antítese das proposições das Organizações das Nações Unidas (ONU) destinadas à exortação do papel da mulher na sociedade. 
partido, já que no fluxo nervoso dessas redes os partidos políticos encabeçam as proposições de Miguel Nagib em suas frentes de representação. O próprio Presidente Jair Bolsonaro teve como plataforma de sua campanha o banimento do pensamento crítico, o "politicamente correto" e a suposta militância de esquerda das escolas e universidades. Dispositivos criados pelo Movimento como pareceres, notas técnicas e mesmo requerimentos de informação sustentam a tentativa de se impor constitucionalmente os PLs; e mais: demarcam preceitos, orientações e condutas denuncistas quanto à utilização dos termos gênero, comunismo, feminismo e diversidade sexual em âmbito político nacional.

Nessa genealogia, uma das primeiras investidas tomou forma no PL no 7.180/2014 (BRASIL, 2014a), de autoria do Sr. Erivelton Santana (Patriota), propondo alterar a LDB/1996 e as diretrizes educacionais. Entre as proposições estão o:

Art. 3 [...] - XIII - respeito às convicções do aluno, de seus pais ou responsáveis, tendo os valores de ordem familiar precedência sobre a educação escolar nos aspectos relacionados à educação moral, sexual e religiosa, vedada a transversalidade ou técnicas subliminares no ensino desses temas. (BRASIL, 2014a, p. 1).

O PL se ampara nos princípios do Pacto de São José da Costa Rica, assinado pelo Brasil e outros países por ocasião da Convenção Americana de Direitos Humanos (1969), que dispõe sobre a liberdade pessoal e de direitos humanos, porém obliterando o papel do Estado na educação e impondo uma interpretação generalista baseada na liberdade da família de professar e divulgar sua religião ou crenças em nível individual e também coletivo (BRASIL, 2014a). Sob esse princípio, ao citar temas transversais ou outras técnicas subliminares, o PL abre um território de condenação das questões e discussões sociais que povoam a escola e demoniza a ação docente, rechaçando as perspectivas de debates acerca desses temas (BRASIL, 2014a). ${ }^{7}$

7 O PL tramitou na Câmara dos Deputados e, entre idas e vindas, aguarda novas designações que se sucederão após
Por conseguinte, iniciativas parecidas foram protocoladas e recrudesceram ainda mais as proposições de controle, vigília e constrangimento das práticas docentes. 0 Escola sem Partido passou a adotar a tática de esvaziamento dos princípios constitucionais já amparados pela Carta Magna de 1988 ao tomar para si a defesa da neutralidade escolar, da valorização da diversidade de opiniões e do pluralismo de ideias. Nesse tocante, entre os vários projetos apensados ao PL no 7.180/2014 está o PL noㅜ 867/2015 (BRASIL, 2015a), de Izalci Lucas, articulando, entre as propostas já apresentadas no documento de 2013, a premissa de inserção do Programa Escola sem Partido como parte da LDB/1996. Destaca-se da redação a imposição de um código de conduta para professoras(es) baseado na negação das posturas docentes e na censura, como se observa na descrição do Art. $4^{\circ}$ e e seus incisos:

No exercício de suas funções, o professor:

I - não se aproveitará da audiência cativa dos alunos, com o objetivo de cooptá-los para esta ou aquela corrente política, ideológica ou partidária;

II - não favorecerá nem prejudicará os alunos em razão de suas convicções políticas, ideológicas, morais ou religiosas, ou da falta delas;

III - não fará propaganda político-partidária em sala de aula nem incitará seus alunos a participar de manifestações, atos públicos e passeatas;

IV - ao tratar de questões políticas, socioculturais e econômicas, apresentará aos alunos, de forma justa, as principais versões, teorias, opiniões e perspectivas concorrentes a respeito;

$\mathrm{V}$ - respeitará o direito dos pais a que seus filhos recebam a educação moral que esteja de acordo com suas próprias convicções;

VI - não permitirá que os direitos assegurados nos itens anteriores sejam violados pela ação de terceiros, dentro da sala de aula. (BRASIL, 2015a, p. 2).

Nesse ínterim, começa a se delinear com clareza uma concepção ideológica e sexuada da

a formação, em dezembro de 2019, de Comissão Especial responsável pelo tema Escola sem Partido nos dispositivos arregimentados na casa. 
escola e de seus aparatos didáticos, conforme dispõem os argumentos e justificativas defendidas no referido PL:

É fato notório que professores e autores de livros didáticos vêm-se utilizando de suas aulas e de suas obras para tentar obter a adesão dos estudantes a determinadas correntes políticas e ideológicas; e para fazer com que eles adotem padrões de julgamento e de conduta moral especialmente moral sexual - incompatíveis com os que lhes são ensinados por seus pais ou responsáveis. (BRASIL, 2015a, p. 4).

Esse alinhamento é o que pretexta a criação pelo PL de "[...] medidas eficazes para prevenir a prática da doutrinação política e ideológica nas escolas, e a usurpação do direito dos pais a que seus filhos recebam a educação moral que esteja de acordo com suas próprias convicções" (BRASIL, 2015a, p. 4).

Vale ressaltar que, em meio a esse turbilhão de condenações e perseguições os quais as/os representantes dessas correntes buscam consolidar, há, em contraposição e resistência, a elaboração e a publicação pelo Fórum Nacional de Educação (FNE) - responsável por organizar a Conferência Nacional de Educação (CONAE) - do documento final da CONAE 2014 (FÓRUM NACIONAL DE EDUCAÇÃO, 2014). Resultado de um amplo processo de construção coletiva desencadeado pela decisão política de submeter ao debate social as ideias e proposições do PNE, tal documento constitui-se como um importante referencial para o processo de mobilização, amparo e retomada das discussões a respeito da igualdade e identidade de gênero e de orientação sexual, mantendo, em paralelo, algumas assertivas e determinações suprimidas na aprovação da Lei no $13.005 / 2014$ (BRASIL, 2014b) e respaldando, ao contrário das denegações do Escola sem Partido, a posição política das(os) representantes do Fórum Nacional da Educação.

Em maio de 2015, o mesmo Izalci Lucas, em coautoria com Cesar Souza, Diego Garcia e Eduardo Cury, protocola o Requerimento de Informação (RIC) n 565/2015 (BRASIL, 2015b), direcionado ao MEC, solicitando, prontamente, informações sobre a publicação do documento derivado da CONAE 2014, sob a alegação de ele ter definido uma posição contrária ao que fora estabelecido durante a votação do PNE, optando por manter a menção ao gênero como diretriz obrigatória para o planejamento e execução de metas e de políticas educacionais no Brasil.

Conforme atestam as proposições da solicitação, novamente há o levante da suposta bandeira de luta contra pressupostos ideológicos ancorados no comunismo, ligados aos ideais marxistas e na suposta ideologia de gênero. 0 RIC $n^{\circ}$ 565/2015 (BRASIL, 2015b) enquadra e denuncia as ações do FNE e também do MEC, interpretando-as como doutrinárias e contrariamente ligadas aos ideais da família. Cita teóricas e ativistas feministas como Judith Butler (propositora do conceito de performatividade das masculinidades e feminilidades a partir de negociações, reiterações ou rompimentos com a matriz heterossexual), Kate Millet (que em seu livro Política Sexual teceu um panorama histórico dos sistemas de exclusão político, jurídico e cultural de mulheres), Shulamith Firestone (questionadora da apropriação do trabalho reprodutivo das mulheres, da gravidez e criação de filhos como a raiz da opressão feminina), os estudos sobre trabalho e família e indústria cultural derivados das críticas da Escola de Frankfurt e as Conferências da ONU como fiéis depositários do comunismo antifamília de Karl Marx e Friedrich Engels.

Para respaldar o argumento, o requerimento vale-se de justificativas distorcidas ao explicar uma suposta guerra cultural e sexual de cunho neomarxista:

O que verdadeiramente está acontecendo é que o conceito de 'Gênero' está sendo utilizado para promover uma revolução cultural sexual de orientação neomarxista com o objetivo de extinguir da textura social a instituição familiar. Na submissão do feminino ao masculino através da família, Marx e Engels enxergaram o protótipo de todos os subsequentes sistemas de poder. Se esta submissão é consequência da biologia, 
não há nada a que se fazer. Mas se ela é uma construção social, ou um Gênero, então, a longo prazo, ela poderá ser modificada até chegar-se à uma completa igualdade onde não haverá mais possibilidade de opressão de Gênero, mas também onde não haverá mais famílias, tanto as heterossexuais como demais famílias alternativas. Neste contexto a educação caberia como uma tarefa exclusiva do Estado, e não existiria mais traços diferenciais entre o masculino e o feminino. Em um mundo de genuína igualdade, segundo esta concepção, todos teriam que ser educados como bissexuais e a masculinidade e a feminilidade deixariam de ser naturais (BRASIL, 2015b, p. 17, grifo do autor).

Dessa leitura, há a produção de uma discursividade que, por argumentos falaciosos e deturpados das teorias que produziram as noções e os conceitos de gênero, distorce as proposições fundamentais alicerçadas em debates científicos e na voz da militância de mulheres e de LGBT+, produzindo afirmações de cunho generalistas e pseudouniversais, como, por exemplo, a destruição do sexo biológico assegurado pelo binarismo "macho-homem / fêmea-mulher" e da família natural.

0 grande objetivo por trás de todo este absurdo - que, de tão absurdo, é absurdamente difícil de ser explicado - é a pulverização da família com a finalidade do estabelecimento de um caos no qual a pessoa se torne um indivíduo solto, facilmente manipulável. A ideologia de Gênero é uma teoria que supõe uma visão totalitarista do mundo. (OLIVEIRA, 2014 apud BRASIL, 2015b, p. 18).

Tais concepções nada representam, de fato, as reinvindicações feministas e LGBT+ no que se atém à defesa pela igualdade de gênero, pela diversidade sexual e pelo apelo de que tais reflexões sejam permitidas nos ambientes escolares.

Essa discursividade que liga o sexo nãofamiliar ou normativo e as militâncias por direitos sexuais e de gênero com o comunismo, tecendo uma sombra de corrupção, fraqueza política ou deturpação do Estado, das escolas e da família não é novidade. Ela já insurgiu no Brasil, conforme assinalamos na introdução deste texto, com a descrição das posições militares sobre as instituições de ensino, e segue sendo sustentada por uma vontade de saber para governar e controlar mentes, sexualidades, desejos e políticas para a população. De acordo com Gayle Rubin (2003), os setores de extrema-direita sempre souberam atacar a educação sexual como um conspiração comunista para destruir a família e enfraquecer as vontades nacionais, debilitar os tabus religiosos, promover a aceitação de relações sexuais anormais, distorcer os padrões normais e destruir a coesão sexo-gênero, rebaixando as pessoas (especialmente brancas) a delírios sexuais como homossexualidade, pornografia, aborto, sexo e relacionamentos extraconjugais.

Essa discursividade vem sendo recuperada e legitimada dentro de uma pseudopolítica que coliga apelos econômicos aos discursos dogmáticos de defesa moral da honra, da tradição familiar e da nação brasileira, enfraquecendo as conquistas e avanços progressistas para a consolidação de uma educação para os gêneros e as sexualidades. Logo, frentes com estrategistas conservadores, de extrema-direita e fundamentalistas religiosos (re)descobriram, portanto, que estes assuntos têm apelo de massa no Brasil.

Em revide ao requerimento de Izalci Lucas, o FNE, após os debates suscitados por proposições dessas frentes, publicou a $32^{\text {a }}$ Nota Pública do Fórum Nacional de Educação (FÓRUM NACIONAL DE EDUCAÇÃO, 2015), questionando os atos discriminatórios e de retirada dos debates de gênero dos documentos oficiais da Educação - PNE e Base Nacional Comum Curricular (BNCC) -, expondo, também, o ataque dos(as) disseminadores dessa falsa premissa ancorada no neologismo ideologia de gênero e seus desserviços ao debate democrático para a construção das políticas educacionais de respeito ao gênero e à diversidade sexual (FNE, 2015).

O Escola sem Partido não mais se desvinculou dessa orquestração, via manipulação de mecanismos legais, de processos autoritários 
para a manipulação da massa em defesa dos valores fundamentalistas.

Em 2016, em mais uma tentativa encampada pelo então Senador Magno Malta, outro dispositivo na forma do PL $\mathrm{n}^{\circ}$ 193/2016 (BRASIL, 2016) visa feriar a LDB/1996, reproduzindo os aspectos elencados nas propostas anteriores para caracterizar ainda mais o Movimento como proposta educacional no âmbito legal e oficializar as práticas de censura e vigilância. Entre outras premissas, o PL fundamenta suas justificativas asseverando que:

O Poder Público não se imiscuirá na opção sexual dos alunos nem permitirá qualquer prática capaz de comprometer, precipitar ou direcionar o natural amadurecimento e desenvolvimento de sua personalidade, em harmonia com a respectiva identidade biológica de sexo, sendo vedada, especialmente, a aplicação dos postulados da teoria ou ideologia de gênero. (BRASIL, 2016, p. 1-2).

Contundentemente, esse PL se apoia numa rebiologização do desenvolvimento humano e da sexualidade como possível constitutivo da LDB/1996, além de abrir precedentes para a definitiva proibição das temáticas de gênero nas escolas. Felizmente, após pressão popular no Senado, o projeto foi retirado de pauta pelo pastor Magno Malta.

Ao final de 2019, entre idas e vindas dos PLs, arquivamentos das proposições, pedidos de desarquivamento, manifestações pró e contra Escola sem Partido, a Deputada Bia Kicis (ex-PSL e atualmente sem partido) apresenta, apensado ao PL no 867/2015 (BRASIL, 2015a), o PL no 246/2019 (BRASIL, 2019), que institui o Programa Escola sem Partido, no formato das mesmas proposições aqui citadas, mas com maior respaldo à caçada às bruxas contra professoras(es) assegurando, entre as principais mudanças em relação aos demais PL: a) o direito de gravação de aulas pelas/pelos estudantes a fim de monitorar os conteúdos escolares e de viabilizar o pleno direito da família sobre as/os educadores; b) a obrigatoriedade das escolas na entrega prévia de materiais informativos so- bre os conteúdos e planejamentos para a vigília dos enfoques adotados; c) a livre imposição de ideologias específicas e de cunho religioso e moral nas escolas confessionais e particulares; e d) a proibição de manifestações políticas nos grêmios estudantis. E mais: conforme o Art. 9oㅡ, aplica o Escola sem Partido:

I - às políticas e planos educacionais;

II - aos conteúdos curriculares;

III - aos projetos pedagógicos das escolas;

IV - aos materiais didáticos e paradidáticos;

$\mathrm{V}$ - às avaliações para o ingresso no ensino superior;

VI - às provas de concurso para ingresso na carreira docente (BRASIL, 2019, p. 2).

Por esses e outros intentos, o projeto de Bia Kicis torna-se o mais persecutório em termos da instalação do poder de vigilância sobre a autonomia escolar e da junção gênero-comunismo.

Essa eloquência também é incessantemente recobrada nas redes sociais do Escola sem Partido. A Nota Técnica redigida por Nagib e outros (2018) e disponibilizada em sites alega que professoras(es) militantes aprenderam e acreditam na doutrinação, engajando suas/seus alunas(os) no pensamento crítico que assimila as ideologias comunistas e de gênero. 0 mesmo ideário "impera no meio acadêmico, onde há a mais completa e proposital ignorância sobre os limites jurídicos da atividade docente, ignorância que deriva em parte da propositada e ilícita ausência de disciplina obrigatória de ética do magistério nos cursos de formação de professores" (NAGIB et al., 2018, p. 2).

De modo geral, os respaldos técnicos escritos por Nagib tentam legalizar notificações extrajudiciais que se aplicariam às/aos professoras(es) que promoveriam discussões políticas, intervenções pedagógicas de educação sexual, debates acerca dos direitos de minorias, críticas aos sistemas econômicos hegemônicos e ao poder estatal, além de exigir a afixação de cartazes com deveres docentes em salas de 
aula. Assim, em conjunto com a apresentação desses dispositivos, há chamadas públicas e convocações do Movimento conclamando pais, familiares e a sociedade civil como um todo para que vigiem as ações docentes que possam ser contrárias aos princípios e valores instituídos pela família tradicional e pelos princípios neoliberais defendidos.

As chamadas conclamam: "Diga não à doutrinação nas escolas e universidades. Junte-se ao Escola sem Partido" (ESCOLA SEM PARTIDO, 2020). E elas se defendem como uma iniciativa contra o uso das escolas e universidades para fins de propaganda ideológica, política e partidária. "Se você ou seu filho foi ou está sendo vítima de algum militante disfarçado de professor, denuncie" (ESCOLA SEM PARTIDO, 2020).

Destarte, analisando os PLs e as manifestações públicas das(os) defensoras(es) do Escola sem Partido, observamos a instauração de outras discursividades a buscar a consolidação dessa visão de educação baseada na "neutralidade política" e livre de ideologias e o adensar de significados negativos à sua discursividade mor: descontaminação comunista e ideóloga de gênero. Citamos, ainda que brevemente, algumas delas: a) a própria ideia de descontaminação, de limpeza da escola e das universidades das posições contrárias ao poder hegemônico; b) a convicção de que existe um inimigo da educação bem regrada - no caso, as/os próprias(os) professoras(as); c) a ideia de estudantes "tabula rasa" como depositárias(os) da doutrinação e da corrupção dos valores morais; e d) o incentivo para se romper os limites entre a educação pública/coletiva (de ordem estatal e laica) e a educação privada (de ordem familiar e endossada por certos valores de grupos particulares, entre eles, as igrejas).

\section{É possível ir contra à pedagogia fascista do escola sem partido?}

O Brasil atravessa um período de demonização dos estudos de gênero, das proposições feministas e da militância LGBT+ sobre os direitos das pessoas cujos gêneros e as sexualidades não coincidem com os marcadores sociais cisgêneros e heteronormativos e lutam por reconhecimento, por direitos sexuais, reprodutivos e por políticas públicas de amparo à não violência sexual e à disseminação de preconceitos e sexismos. Como afirma Miguel (2016), é perceptível a presença de enunciados em que a desigualdade é exaltada com discursos reacionários conjugados a uma visão de "libertarianismo", fundamentalismo religioso e a recuperação do antigo anticomunismo.

Nesse contexto, tal projeto de sociedade e de educação impede que haja questionamentos quanto às diferentes desigualdades sofridas em relação aos papéis sexuais, às identidades de gênero e às violências diversas, inclusive dentre e fora das instituições escolares.

A falácia da neutralidade baseia-se na ficção de um conhecimento não situado socialmente. Percepções críticas que apontam injustiças e suas contradições não passam pelo crivo da neutralidade e, nesse sentido, corroboram para invisibilizar e naturalizar as diversas formas de opressões na ordem vigente, cruciais à sua reprodução.

Importa destacar e marcar sempre que, no seio da implantação de uma pedagogia que assume um caráter fascista de imposição de falsas verdades, medos e perseguições, há uma descaracterização espúria do que é a discussão sobre gênero e o papel de teorias como o materialismo histórico dialético para a compreensão da sociedade.

Dessa forma, o projeto de educação almejado pelas(os) defensoras(es) do Escola sem Partido é incapaz de produzir transformações significativas na realidade social, dado que se torna o disseminador de ideias deturpadas que chancelam injustiças e violências. Há em cena, portanto, não a valorização de uma escola que não produzirá pessoas autônomas, críticas e pensantes, mas, sim, de sujeitos a defender conservadorismos morais e um ultraliberalismo econômico, baseado nas falácias das 
conquistas individuais com base no esforço (meritocracia), no empreendedorismo de si, no distanciamento dos grupos minoritários e da luta por seus reconhecimentos, na ausência de pensamento crítico, na colonização das mentes e na manutenção dos problemas estruturais e estruturantes de nossa sociedade. Esse tipo de educação desconsidera todos os condicionantes históricos do país e suas marcas de desigualdades.

Essas assunções penetram nas massas e engrossam contextos políticos que (re)produzem, em meio ao caos e ao pânico, o medo de um comunismo latino (o bolivarismo, por exemplo) e de uma ditadura gay.

Nesse contexto, mesmo dispondo de instrumentos legais que demonstram que iniciativas como o Escola sem Partido nasceram eivadas de inconstitucionalidade, como defendeu a Nota Técnica emitida pelo Ministério Público Federal - Nota Técnica 01/2016, PFDC, assinada pela Procuradora Deborah Duprat, que dispõe sobre a inconstitucionalidade das notificações e do ESP (MINISTÉRIO PÚBLICO FEDERAL, 2016), ainda há a insistência e a disseminação de processos persecutórios que produzem medo e censura nas(os) agentes da educação.

No entanto, não podemos minimizar a força dos dispositivos legais que temos para barrar os avanços conservadores. Conforme explicita a referida Nota Técnica, o que se revela nesses movimentos e nos PLs do Escola sem Partido é:

[...] o inconformismo com a vitória das diversas lutas emancipatórias no processo constituinte; com a formatação de uma sociedade que tem que estar aberta a múltiplas e diferentes visões de mundo; com o fato de a escola ser um lugar estratégico para a emancipação política e para o fim das ideologias sexistas - que condenam a mulher a uma posição naturalmente inferior, racistas - que representam os não-brancos como os selvagens perpétuos, religiosas - que apresentam o mundo como a criação dos deuses, e de tantas outras que pretendem fulminar as versões contrastantes das verdades que pregam. (MINISTÉRIO PÚBLICO FEDERAL, 2016, p. 2).
Temos a nosso favor as pressões da ONU e cobranças de posições do Brasil sobre o avanço dessa escola antidemocrática, como, também, o posicionamento do Supremo Tribunal Federal a suspender as ações do Escola sem Partido em alguns estados e cidades e para conscientizar professoras(es) e políticas(os) a não consentirem com os dispositivos criados por Nagib e apoiadoras(es).

Ainda nesse contexto de reprodução e falta de discernimento quanto aos processos de consolidação da censura e da valorização de alguns modelos de sociedade, é urgente pensar em estratégias para não sucumbir a uma pedagogia fascista.

Boaventura de Sousa Santos (2006) critica o modelo de racionalidade ocidental nesse tipo de empreendimento pedagógico. Para ele, a tradição ocidental é responsável por desacreditar ou esconder as alternativas de experiência social em todo o mundo. Por alternativas, entendemos todos os movimentos que buscam questionar padrões de dominação, de submissão e esgotamentos políticos gestados por uma ordem social que produz desigualdades. Para tanto, critica o que ele chama de razão indolente ${ }^{8}$ pautada na tradição ocidental que contrai o presente e expande o futuro, pois gera várias consequências nefastas na sociedade de globalização neoliberal.

Isso significa dizer que a indolência da razão criticada por esse autor causa consequências no modo como as culturas se organizam. Essa razão, como afirma Santos (2006), não é apenas parcial, mas internamente muito seletiva, tendo uma compreensão limitada de si própria.

8 A indolência da razão criticada por esse autor ocorre em quatro formas diferentes: a razão impotente, a razão arrogante, a razão metonímica e a razão proléptica. Santos (2002a) vincula sua crítica fundamentalmente a partir das duas últimas razões, menos centradas nos estudos críticos. A razão metonímica é obcecada pela ideia da totalidade sob a forma da ordem. Todas as dicotomias sufragadas pela razão metonímica contêm uma hierarquia: "cultura científica/cultura literária; conhecimento científico/ conhecimento tradicional; homem/mulher; cultura/ natureza; civilizado/primitivo; capital/trabalho; branco/ negro; norte/sul; Ocidente/Oriente; e assim por diante." (SANTOS, 2002a, p. 242). 
É preciso pensar os termos das dicotomias fora das articulações e relações de poder que os unem, revelando outras relações alternativas que têm estado ofuscadas pelas dicotomias hegemônicas. E é por isso que trazemos ao centro das discussões a sociologia da ausência e a sociologia da emergência. A sociologia das ausências trata-se, fundamentalmente,

[...] de uma investigação que visa demonstrar que o que não existe é, na verdade, activamente produzido como tal, isto é, como uma alternativa não-credível ao que existe. [...] o objectivo da sociologia das ausências é transformar objectos impossíveis em possíveis e com base neles transformar as ausências em presenças. [...] Há produção de não-existência sempre que uma dada entidade é desqualificada e tornada invisível, ininteligível ou descartável de um modo irreversível. (SANTOS, 2002a, p. 246).

O ESP procura desqualificar os saberes produzidos por correntes de pensamento que não se coadunam à lógica defendida pelas(os) suas/seus disseminadoras(es). Dessa produção da não-existência, apresentamos cinco monoculturas que são distinguidas por Santos (2002a): a monocultura do saber e do rigor do saber, transformando a ciência moderna e a alta cultura em critérios únicos de verdade e validade estética; a monocultura do tempo linear, considerando a história como tendo sentido e direção únicos e conhecidos, assim a modernidade ocidental produz a não-contemporaneidade do contemporâneo, recuperando, por exemplo, discursos e procedimentos de censura já observados ao longo da história; a lógica da classificação social que se assenta na monocultura da naturalização das diferenças, distribuindo a população por categorias que naturalizam hierarquias, como, por exemplo, a classificação racial e a classificação sexual, enquadrando as/os sujeitos no discursos de moralidade e perversão; a lógica da escala dominante, produzindo a não-existência do particular e do local, produzindo noções universais e pouco representativas da diversidade que compõe o país; e a lógica produtivista que se assenta na monocultura dos critérios de produtividade capitalista. Ciente dessas cinco lógicas de produção da não-existência, a sociologia das ausências visa criar condições para ampliar o campo das experiências credíveis neste mundo, contribuindo para dilatar o presente. Nesse sentido, propõe a superação das totalidades homogêneas e excludentes da razão metonímica, sugerindo a permuta das cinco lógicas apontadas por outras denominadas: ecologia de saberes, substituindo a monocultura do saber científico e apontando para a necessidade de se considerar conhecimentos não-hegemônicos e/ou naturalizados como tais; ecologia das temporalidades, libertando as práticas sociais do seu estatuto de resíduo, possibilitando um desenvolvimento autônomo e reconhecendo que a história não é linear e, por isso mesmo, produz diferentes narrativas e possibilidades de um outro olhar; ecologia dos reconhecimentos, consistindo em uma nova articulação entre o princípio da igualdade e o princípio da diferença e abrindo espaço para a possibilidade de diferenças iguais e reconhecimento recíproco, valorizando o outro nesse processo e reconstruindo outras lógicas não discriminatórias; a ecologia das trans-escalas, visando à possibilidade de uma globalização contra-hegemônica, superando o pensamento abissal, que produz e radicaliza distinções; e a ecologia de produtividade, reconstruindo essas formas para além da relação de subalternidade da lógica produtivista (SANTOS, 2002a).

É nesses pilares que também nos apoiamos, considerando que é preciso haver uma dimensão desconstrutiva e uma dimensão reconstrutiva, priorizando a modificação das lógicas que vigoram na sociedade moderna, apresentadas por Santos (2002a). E, enquanto a dilatação do presente é feita através da sociologia das ausências, a contração do futuro se realiza através da sociologia das emergências, produzindo um futuro de possibilidades plurais e concretas simultaneamente utópicas e realistas, que se vão construindo no presente, diante de um horizonte de possibilidades. Dessa forma, o que se nos apresenta não é tanto identificar 
novas totalidades, mas propor novas formas de pensar, de desconstruir essas totalidades e de conceber outros sentidos. Precisamos pensar que qualquer dicotomia tem uma vida para além da vida dicotômica. Precisamos superar a falsa dualidade dos campos de conhecimento, implodindo o caráter exclusivo de monopólio da produção de verdades que está no cerne da disputa epistemológica moderna vinculada à produção de linhas abissais que impedem a copresença de conhecimentos e experiências no mundo. Essa negação da copresença produz o desperdício de uma vasta gama de experiências, tornadas invisíveis e apartadas dos processos democráticos.

E, nesse quesito, citamos Boaventura de Sousa Santos (2002b), apresentando a sua epistemologia da cegueira e a epistemologia da visão. Propõe esse autor que a cegueira dos outros, em especial dos outros do passado, é tão recorrente quanto fácil de identificar. Todavia, se é assim, provavelmente o que dissermos hoje sobre a cegueira dos outros será visto no futuro como sinal da nossa cegueira. Esse dilema pode ser formulado desta forma: "Se somos cegos, por que vemos tão facilmente a cegueira dos outros e por que razão é tão difícil aceitar a nossa própria cegueira? Por que julgamos ver plenamente o que só vemos muito parcialmente? E se assim é, de que vale sequer ver?" (SANTOS, 2002b, p. 226).

A epistemologia da visão propõe uma forma de saber cujo momento é a solidariedade. Enquanto pela forma hegemónica de conhecimento, conhecemos criando ordem, a epistemologia da visão levanta a questão sobre se é possível conhecer criando solidariedade. A solidariedade como forma de conhecimento é o reconhecimento do outro como igual, sempre que a diferença lhe acarrete inferioridade, e como diferente, sempre que a igualdade lhe ponha em risco a identidade. Tendo sido sobre-socializados por uma forma de conhecimento que conhece impondo ordem, tanto na natureza como na sociedade, é-nos difícil por em prática, ou sequer imaginar, uma forma de conhecimento que conhece criando solidariedade, tanto na natureza como na sociedade. (SANTOS, 2002b, p. 246).
Assim, das duas epistemologias, é possível conceber "a emergência de um conhecimento prudente para uma vida decente" (SANTOS, 2002b, p. 253), um conhecimento que reconhece as experiências e as expectativas, as ações e as consequências, num saber solidário. "A aspiração última é demasiado humana, uma aspiração que designo por normalidade avançada: a aspiração de viver em tempos normais, ou seja, tempos cuja normalidade não derive, como acontece agora, da naturalização da anormalidade." (SANTOS, 2002b, p. 253).

Estamos à procura de "um conhecimento prudente para uma vida decente" (SANTOS, 2002b), um conhecimento que, por meio da solidariedade, não reproduza mais os modelos discriminatórios que produzem exclusões.

Assim, valorizamos a superação ora recuperada pelo ESP de uma educação meramente bancária, supondo educandos(as) como seres de adaptação e ajustamento, visto que tal visão não desenvolve consciência crítica e nem inserção no mundo como sujeitos transformadores (FREIRE, 1987).

Como Paulo Freire (1996) aborda, formar é muito mais do que puramente treinar a/o educanda(o) no desempenho de destrezas. A tarefa docente exige no seu exercício uma responsabilidade ética.

A ética de que falo é a que se sabe traída e negada nos comportamentos grosseiramente imorais como na perversão hipócrita da pureza em puritanismo. A ética de que falo é a que se sabe afrontada na manifestação discriminatória de raça, de gênero, de classe. É por essa ética inseparável da prática educativa, não importa se trabalhamos com crianças, jovens ou com adultos, que devemos lutar. E a melhor maneira de por ela lutar é vivê-la em nossa prática, é testemunhá-la, vivaz, aos educandos em nossas relações com eles. (FREIRE, 1996, p. 9-10).

Mulheres e homens se tornam seres éticos por sua capacidade de comparar, valorar, intervir, escolher, decidir e de romper, romper com situações que não possibilitem o respeito à natureza do ser humano. Nesse contexto, toda ação é política, mesmo aquelas travestidas de 
certa neutralidade. Basta saber: o direcionamento dado à ação baseia-se na ética como compromisso político ou na deturpação e reprodução dos valores consagrados por uma racionalidade mercadológica, sexista, homofóbica e definitivamente pouco democrática e humana? Fazer-se essa pergunta é um convite à superação das pedagogias fascistas e das escolas de pensamento único e totalitário.

\section{Considerações finais}

O ESP estabelece obrigações morais, condenações, patrulhamento de conteúdos históricos, socioculturais e econômicos em razão de uma educação totalmente técnica, descontextualizada, acrítica e pseudocientífica. Também propõe, como um instrumento de censura, a gravação das aulas pela(o) estudante, visando instaurar um ambiente de coerção, perseguição e vigilância ao trabalho docente. Além disso, abre fraturas para o desmantelamento da escola pública, aumentando a interferência do poder privado no fórum coletivo escolar, quebrando com a gestão comunitária dos conteúdos e dos projetos políticos pedagógicos das instituições. Em termos de história, sua aversão ao comunismo não é uma nova discursividade e sua base de sustentação de caça às/aos subversivas(os) resgata as proposições anteriormente usadas como estratégia de convencimento pelas(os) apoiadoras(es) do regime de Ditadura Militar

Nesse sentido, o movimento sustenta a interferência parental nas escolas e a firme posição de que nenhum docente ou conteúdo escolar pode atentar contra as convicções morais e religiosas das famílias, devendo a pessoa doutrinadora ser denunciada à direção da escola, às Secretarias de Educação e ao Ministério Público. Para serem fiéis ao pensamento do núcleo familiar, os ensinamentos escolares devem ser parciais, ou seja, são proibidos os conteúdos científicos e os pontos de vistas que necessitam da análise crítica sobre suas correlações históricas, políticas e sociais; sendo assim, a neutralidade de educadoras(es) e de livros didáticos é uma discursividade disseminada pelas(os) adeptas(os) do Escola sem Partido.

Antes, a ideia de uma Escola sem Partido focava, sobretudo, no temor à doutrinação marxista. Mais tarde, encampando a bandeira de grupos religiosos conservadores, promovese a cruzada contra as discussões sobre papéis de gênero e combate à homofobia e ao sexismo nas escolas, alimentada pela ideia fantasiosa da ideologia de gênero. Assim, o discurso construído pelo Movimento Escola sem Partido passa a basear-se na defesa de uma educação "neutra" que se consolide com a doutrina da família cristã, impedindo professoras e professores de disseminarem, em sala de aula, qualquer conteúdo que seja contrário aos valores do mercado e das famílias "tradicionais" brasileiras.

Quando refletimos sobre a quem ou para quê serve a escolarização nos moldes de hoje, percebemos que a igualdade, a democracia, a garantia dos direitos tão proclamados nos discursos hegemônicos atendem primordialmente às demandas dos grupos dominantes, encampados pelo discurso da neutralidade e do pluralismo de ideias, que na prática nada tem de plural. A escola tem contribuído de modo significativo para a elaboração das identidades sociais e culturais dos sujeitos, tornando-se um espaço onde a norma é muito mais que necessária, ela é fundamental para a sua manutenção. 0 discurso da inclusão e do respeito às diferenças, muitas vezes, passa por uma série de filtros que demarcam os limites dessa transformação e que guiam as ações docentes para a reprodução de campos de saberes recheados de táticas de controle e coerção social.

No domínio da produção de conhecimentos, da apropriação de um discurso de limpeza dos vícios morais e da deturpação dos conhecimentos científicos, o Movimento Escola sem Partido vai instaurando uma dinâmica de conversão e doutrinação aos moldes da família cristã e do pensamento político neoliberal. Ao contrário do que o Escola sem Partido prega, há o exer- 
cício da proibição e da censura aos diferentes campos de conhecimento e produção de saberes, numa adoção forçada às normas que regem as discursividades produzidas pelo movimento em sua monocultura de saberes. Utilizando-se de aparatos legais e normativos, impõe-se uma forma particularmente complexa de perseguição às/aos docentes que ultrapassam as linhas abissais, tensionando estratégias de controle e regulação impostas pelas doutrinas disseminadas no pensamento de uma escola única.

A linha abissal jurídica e epistemológica constituída pelo Movimento envolve a incorporação, cooptação e assimilação de alguns mitos que foram marcadores históricos de subversão, como as ideias comunistas, a liberdade sexual e a adoção de práticas moralmente condenáveis, entre elas a homoafetividade, a luta por direitos sexuais e reprodutivos, o reconhecimento da diversidade cultural e a luta pelo reconhecimento dos grupos identitários considerados minorias sociais. $\mathrm{O}$ uso manipulador do direito e da autoridade no Escola sem Partido representam, pois, um modelo de exclusão radical que, em casos representativos da atual política de Estado, demonstram os rumos repetidamente traçados pelas(os) suas/seus representantes e por suas redes de atuação (ministérios, assessoria e defensoras(es) da atual lógica governamental, por exemplo).

Desse modo, a complexidade desse Movimento é difícil de destrinchar na medida em que se desenrola ante os nossos olhos. Para captar a totalidade do que está acontecendo, é necessário um esforço enorme de descentramento, um movimento contra-hegemônico, uma análise genealógica das produções e contraproduções discursivas que vão embasar o cenário de disputas que constituem o Movimento Escola sem Partido e os seus fundamentalismos circundantes. Vemos delinear a ascensão de fascismos sociais, baseados em relações de poder extremamente desiguais que coexistem com a democracia política liberal. Trata-se, como apontado por Santos (2017), de um fascismo pluralista e, por isso, de uma forma de fascismo que nunca existiu, dado que as sociedades são politicamente democráticas e socialmente fascistas.

Para tanto, é essencial que, como educadoras e educadores, possamos vislumbrar possibilidades que ultrapassem lógicas centradas na monocultura de saberes baseadas na suposta universalidade dos conhecimentos, identidades e subjetividades. É urgente a assunção de uma postura de combate e resistência, para não sucumbir à uma pedagogia fascista aliada aos ditames de certos grupos políticos conservadores e ultraliberais. Sendo territórios de disputa (epistemológica, política e jurídica), precisamos estar atentas(os) aos modos como tais discursividades se infiltram nos diferentes espaços, visando a produção de conhecimentos alternativos, cosmopolitas, contra-hegemônicos e que sejam instrumentos de luta contra exclusões de ordem econômica, social, política e cultural geradas pela globalização neoliberal.

\section{REFERÊNCIAS}

BRASIL. Câmara dos Deputados. Projeto de Lei no 8035-C, de 2010. Substitutivo do Senado Federal ao Projeto de Lei № 8.035-B, DE 2010, que "Aprova o Plano Nacional de Educação (PNE) e dá outras providências". Brasília, DF, 2010. Disponível em: https://www2.camara.leg.br/ atividade-legislativa/comissoes/comissoestemporarias/especiais/54a-legislatura/pl-803510-plano-nacional-de-educacao/documentos/ outros-documentos/avulso-pl-8035-10-c. Acesso em: 20 fev. 2020.

BRASIL. Câmara dos Deputados. Projeto de Lei no 7.180, de 2014. Altera o art. $3^{\circ}$ da Lei $n^{\circ}$ 9.394, de 20 de dezembro de 1996, que estabelece as diretrizes e bases da educação nacional. Brasília, DF, 2014a. Disponível em: https://www.camara. leg.br/proposicoesWeb/prop_mostrarintegra?cod teor $=1230836 \&$ filename $=P L+7180 / 2014$. Acesso em: 11 fev. 2020.

BRASIL. Presidência da República. Casa Civil. Lei no 13.005, de 25 de junho de 2014. Aprova o Plano Nacional de Educação - PNE e dá outras providências. Brasília, DF, 25 jun. 2014b. Disponível em: http://www.planalto.gov.br/ccivil_03/_ato20112014/2014/lei/l13005.htm. Acesso em: 20 fev. 2020. 
BRASIL. Câmara dos Deputados. Projeto de Lei no 867, de 23 de março de 2015. Inclui, entre as diretrizes e bases da educação nacional, o Programa Escola sem Partido. Brasília, DF, 2015a. Disponível em: https://www.camara.leg.br/proposicoesWeb/ fichadetramitacao?idProposicao $=1050668$. Acesso em: 11 fev. 2020.

BRASIL. Câmara dos Deputados. Requerimento de Informação no $\mathbf{5 6 5}$, de 2015. Requer ao Ministro de Estado da Educação informações sobre o Documento Final do Conae-2014, assinado e apresentado pelo Fórum Nacional de Educação como passo na articulação da educação nacional como política de Estado, no qual define, contrariamente ao que foi estabelecido durante a votação do PNE nesta casa, a ideologia de gênero como diretriz obrigatória para o PNE, o planejamento e as políticas educacionais no Brasil. Brasília, DF, 2015b. Disponível em: https://www. camara.leg.br/proposicoesWeb/prop_mostrarinte gra? codteor $=1337320 \&$ filename $=$ RIC $+565 / 2015$. Acesso em: 11 fev. 2020.

BRASIL. Senado Federal. Projeto de Lei no 193, de 2016. Inclui entre as diretrizes e bases da educação nacional, de que trata a Lei no 9.394 , de 20 de dezembro de 1996, o "Programa Escola sem Partido". Brasília, DF, 2016. Disponível em: https:// legis.senado.leg.br/sdleg-getter/documento?dm=3 410752\&ts=1567535329994\&disposition=inline. Acesso em: 11 fev. 2020.

BRASIL. Câmara dos Deputados. Projeto de Lei no 246, de 04 de fevereiro de 2019. Institui o Programa Escola sem Partido. Brasília, DF, 2019. Disponível em: https://www.camara.leg.br/ proposicoesWeb/fichadetramitacao?idProposic ao=2190752. Acesso em: 11 abr. 2019.

CARVALHO, Fabiana Aparecida de; POLIZEL, Alexandre Luiz; MAIO, Eliane Rose. Uma escola sem partido: discursividade, currículos e movimentos sociais. Semina: Ciências Sociais e Humanas, Londrina, PR, v. 37, n. 2, p. 193- 210, 2016.

ESCOLA SEM PARTIDO. Página Inicial. Disponível em: http://escolasempartido.org/. Acesso em: 06 jan. 2020.

FÓRUM NACIONAL DE EDUCAÇÃO (FNE). Documento Final CONAE-2014. 2014. Disponível em: http://fne.mec.gov.br/images/doc/ DocumentoFina240415.pdf. Acesso em: $02 \mathrm{dez}$. 2019.

FÓRUM NACIONAL DE EDUCAÇÃO (FNE). 32a Nota Pública do Fórum Nacional de Educação.
Em defesa do direito à educação e da qualidade social, laica, inclusiva, pública, gratuita e para todos e todas. Brasília, DF, 2015. Disponível em: http:// fne.mec.gov.br/images/notas/32NP3.pdf. Acesso em: 02 dez. 2019.

FOUCAULT, Michel. Microfísica do poder. 4. ed. Rio de Janeiro: Graal, 1984.

FREIRE, Paulo. Pedagogia da autonomia: saberes necessários à prática educativa. São Paulo: Paz e Terra, 1996.

FREIRE, Paulo. Pedagogia do oprimido. 17. ed. Rio de Janeiro: Paz e Terra, 1987.

FURLAN, Cássia Cristina; CARVALHO, Fabiana Aparecida de. Gênero: para além das disputas ideológicas, os amparos legais. In: MAIO, Eliane Rose; OLIVEIRA, Márcio (org.). Gênero, sexualidades e diferenças: categorias de análises, (des) territórios de disputas. Maringá: EDUEM, 2019. p. 61-82.

GARBAGNOLI, Sara; PREARO, Massimo. La croisade anti-genre: du Vatican aux manifs pour tous. Paris: Éditions Textuel, 2017.

MIGUEL, Luis Felipe. Da "doutrinação marxista" à "ideologia de Gênero" - Escola sem Partido e as leis da mordaça no parlamento brasileiro. Direito \& Práxis, Rio de Janeiro, v. 7, n. 15, p. 590-621, 2016.

MINISTÉRIO PÚBLICO FEDERAL. Procuradoria Federal dos Direitos do Cidadão. Nota Técnica 01/2016 PFDC. 2016. Disponível em: http:// pfdc.pgr.mpf.mp.br/temas-de-atuacao/educacao/ saiba-mais/proposicoes-legislativas/nota-tecnica01-2016-pfdc-mpf. Acesso em: 12 fev. 2020.

NAGIB, MIGUEL. Et al. Nota técnica - Escola sem Partido. 2018. Disponível em: https://www.conjur. com.br/dl/nota-tecnica-copia-parecer-escola.pdf. Acesso em: 11 fev. 2020.

PENNA; Fernando de Araújo; SALLES, Diogo da Costa. A dupla certidão de nascimento do Escola sem Partido: analisando as referências intelectuais de uma retórica reacionária. In: MUNIZ, Altemar de Costa Arquivos; LEAL, Tito Barros (org.). Arquivos, documentos e ensino de história: desafios contemporâneos. Fortaleza: EdUECE, 2017. p. 13-38.

RESSTEL, A. Documento infiltração comunista nos meios educacionais. São Paulo: Imprensa do Estado de São Paulo, 1970.

RUBIN, Gayle. Pensando sobre sexo: notas para uma teoria radical da política da sexualidade. Cadernos 
Pagu, Campinas, SP, n. 21, p. 1-88, 2003.

SANTOS, Boaventura de Souza. Para uma sociologia das ausências e uma sociologia das emergências. Revista Crítica de Ciências Sociais, Coimbra, Portugal, v. 63, p. 237-280, out. 2002a.

SANTOS, Boaventura de Souza. A crítica da razão indolente: contra o desperdício da experiência. 4. ed. São Paulo: Cortez, 2002b.

SANTOS, Boaventura de Souza. A gramática do tempo: por uma nova cultura política. São Paulo: Cortez, 2006.
SANTOS, Boaventura de Souza. Para além do pensamento abissal: das linhas globais a uma ecologia de saberes. 2017. Disponível em: https:// www.ces.uc.pt/bss/documentos/Para_alem_do_ pensamento_abissal_RCCS78.PDF. Acesso em: 20 dez. 2019.

TOLOMEOTTI, Tamires; CARVALHO, Fabiana Aparecida de. Um currículo degenerado: os planos de educação e a questão de gênero nos documentos educacionais. Revista Ártemis, v. 22, n. 1, p. 73-84, dez. 2016.

Recebido em: 15/03/2020

Aprovado em: 09/06/2020

(cc) EY-NC Este é um artigo publicado em acesso aberto sob uma licença Creative Commons. 